\section{Maxillary sinus disease: diagnosis and treatment}

\author{
G. W. Bell, ${ }^{1}$ B. B. Joshi and R. I. Macleod ${ }^{3}$
}

VERIFIABLE CPD PAPER
IN BRIEF
- Chronic maxillary sinusitis rarely causes facial pain except in acute exacerbations.
- Acute maxillary sinusitis rarely causes facial swelling.
- Antibiotics are only indicated in acute maxillary sinusitis when infection spreads beyond the confines of the sinus or the patient is systemically unwell.
- Patients with orofacial pain are often inaccurately diagnosed as suffering from sinusitis.

The maxillary sinus is the paranasal sinus that impacts most on the work of the dentist as they will often be required to make a diagnosis in relation to orofacial pain that may be sinogenic in origin. Maxillary sinus disease is often coincidentally observed on radiographs, and dentists often have to make a diagnosis and plan treatment based on the interpretation of the image. This paper aims to guide the dental professional through some of the disease processes involving the paranasal sinuses and in particular the maxillary sinus. The outcome is to encourage comprehensive history taking and examination of the patient to facilitate an accurate diagnosis that will enable successful treatment.

\section{ANATOMY, FUNCTION \\ AND DISEASE OF THE PARANASAL SINUSES}

The paranasal sinuses, along with the turbinates, facilitate the function of the nasal space in the warming and humidification of air and contribute to the body's defences against microbial ingress. ${ }^{1}$ In addition, the paranasal sinuses, named according to the bones within which they lie, are thought to decrease the weight of the facial skeleton and contribute to voice resonance. Although unlikely to have been an evolutionary adaptation or creative feature, the shape and structure of the face and paranasal sinuses may act as a crumple zone in severe trauma, protecting the brain.

The lining of the sinuses (ciliated columnar epithelium) produces mucus, which is moved by the action of cilia in a synchronised pattern around the sinus often against gravity, and in the case of the frontal sinus not by the most direct

"Maxillofacial Associate Specialist, ${ }^{2}$ Consultant Ear Nose and Throat Surgeon, Dumfries \& Galloway Royal Infirmary, Dumfries, DG1 4AP: ${ }^{3}$ Consultant in Dental and Maxillofacial Radiology, Newcastle Dental Hospital, Newcastle, NE2 4BW

*Correspondence to: Dr Garmon Bell

Email: garmon.bell@nhs.net

Tel: +44 (0) 1387246246

\section{Refereed Paper}

Accepted 4 November 2010

DOI: $10.1038 /$ sj.bdj.2011.47

${ }^{\circ}$ British Dental Journal 2011; 210: 113-118 route, to the ostia where drainage occurs into the nasal space. (Fig. 1) From the nasal space the mucus passes into the nasopharynx and is swallowed. In the presence of disease it is the interruption of this basic process, usually by reduced ciliary activity or obstruction, that causes symptoms. The ostia of the anterior ethmoid, frontal and maxillary sinuses are closely approximated in the middle meatus, such that inflammation related to middle meatal soft tissue will often involve more than one sinus.

The ostium of the maxillary sinus is high up on the medial wall and on average is $2.4 \mathrm{~mm}$ in diameter. The bone window is much larger but the effective ostium is reduced by the uncinate process, an extension of the inferior turbinate and the surrounding soft tissues. The maxillary sinus can very occasionally be absent or hypoplastic but usually is the first to develop, showing two main growth spurts at 0-3 years and the second at 7-12 years, corresponding with the development and eruption of the permanent dentition and pubertal facial growth. The molar teeth are in closest relation to the maxillary sinus, with the premolar teeth less so. ${ }^{2}$ Occasionally ectopic canine teeth can be closely related to the maxillary sinus. Growth of the sinus continues through life by a process called pneumonisation, such that the roots of maxillary teeth often project into the air space, and following loss of teeth, the sinus floor

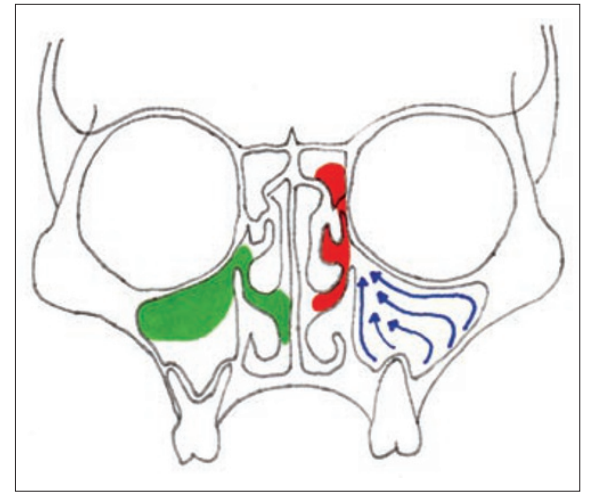

Fig. 1 A coronal section through the sino-nasal complex. The frontal sinuses are not shown. The direction of mucociliary activity in the maxillary sinus is in blue. Ethmoid polyps are in red, with antrochoanal polyps in green

may be at a level below the nasal floor. The right and left sinuses are often of different dimensions.

A broad spectrum of disease processes can involve the maxillary sinus arising either from within the lining of the sinus, the adjacent paranasal sinuses, nasal space, dental and oral tissues, or in the adjacent bone with expansion into the sinus. (Table 1)

\section{Inflammatory paranasal sinus disease}

Inflammatory sinus disease is the most common disease process involving the paranasal sinuses. ${ }^{3}$ When the maxillary sinus is involved, it is the disease entity where a dentist will most often be asked to make a differential diagnosis. 
Most inflammatory paranasal sinus disease causing symptoms of pain occurs within one week following an upper respiratory tract infection, and is usually viral in origin. The term biphasic illness is occasionally used to describe a patient recovering from what is usually a head cold only to become unwell a few days later with facial pain, nasal congestion and discharge. This presentation is what is termed acute rhinosinal disease, and once the diagnosis has been made the aim of treatment is to relieve symptoms. The duration of the illness is usually not influenced by treatment and can last up to four weeks.

Chronic rhinosinal disease is the term generally used to describe nasal congestion or discharge that persists for eight to 12 weeks. Chronic disease rarely causes symptoms of pain except during acute exacerbations, and dentists are unlikely to be presented with a patient who has orofacial pain because of chronic sinus disease. Chronic rhinosinus disease is usually bacterial rather than viral. ${ }^{4}$ Stasis in the maxillary sinus following acute infection as a result of reduced ciliary activity can predispose to bacterial infection. The maxillary sinus is predisposed to stasis due to the ostium being situated high up on the medial wall. However, stasis within the maxillary sinus can also occur due to nasal polyps, most commonly ethmoid polyps, which effectively block the middle meatus and the drainage of the sinuses. ${ }^{5}$ (Fig. 1) Stasis can also occur secondary to anatomical variation such as a deviated nasal septum or a concha bullosa, a bulky pneumatised middle turbinate, both of which impede drainage from the middle meatus.

The diagnostic issue that dentists often encounter is to determine the cause of orofacial pain. Interested readers are directed to the comprehensive review of orofacial pain by Scully and Felix in a previous publication in this journal. ${ }^{6}$ Acute sinusitis that follows an upper respiratory tract infection may cause facial pain, whereas chronic sinusitis is unlikely to. Pain due to tension headache, migraine, atypical facial pain or temporomandibular disorder is often mistaken for sinusitis simply on the basis that the patient locates the source of the pain to the sinonasal region, with the distinction between acute or chronic disease having not been made. ${ }^{7}$ There is

\section{Table 1 Disease processes involving the maxillary sinus}

\begin{tabular}{|c|c|c|}
\hline \multirow[t]{3}{*}{ Inflammation } & Infection & Bacterial/viral/fungal \\
\hline & \multirow[t]{2}{*}{ Allergic } & Polyps \\
\hline & & Fungal \\
\hline \multirow[t]{24}{*}{ Neoplastic } & \multirow[t]{7}{*}{ Benign } & Inverted papilloma \\
\hline & & Osteoma \\
\hline & & Adenomatoid odontogenic tumour \\
\hline & & Keratocystic odontogenic tumour \\
\hline & & Neurofibroma \\
\hline & & Angiofibroma \\
\hline & & Cylindrinoma \\
\hline & \multirow[t]{5}{*}{ Malignant epithelial } & Squamous cell carcinoma and subtypes \\
\hline & & Adenocarcinoma \\
\hline & & Adenoid cystic carcinoma \\
\hline & & Acinic cell carcinoma \\
\hline & & Mucosal melanoma \\
\hline & \multirow[t]{9}{*}{ Malignant non-epithelial } & Soft tissue sarcoma \\
\hline & & Neurogenic sarcoma \\
\hline & & Angiosarcoma \\
\hline & & Leiomyosarcoma \\
\hline & & Rhabdomyosarcoma \\
\hline & & Fibrosarcoma \\
\hline & & Chondrosarcoma \\
\hline & & Osteosarcoma \\
\hline & & Haemangiopericytoma \\
\hline & \multirow[t]{2}{*}{ Malignant lymphoreticular } & Lymphoma \\
\hline & & Plasmacytoma \\
\hline & Metastatic & \\
\hline \multirow[t]{8}{*}{ Odontogenic } & \multirow[t]{3}{*}{ Infection } & Pulpal/periapical \\
\hline & & Periodontal \\
\hline & & Oroantral fistula \\
\hline & \multirow[t]{3}{*}{ Cystic } & Radicular \\
\hline & & Dentigerous \\
\hline & & (Benign neoplastic lesions) \\
\hline & Fibrocemento osseous & \\
\hline & Foreign body & Teeth/implants/restorative materials \\
\hline Mucocele & & (Multifactorial aetiology) \\
\hline \multirow{2}{*}{$\begin{array}{l}\text { Granulomatous } \\
\text { Vasculitis }\end{array}$} & & Wegener's granulomatous \\
\hline & & Churg-Strauss syndrome \\
\hline Silent sinus syndrome & & (Aetiology yet to be fully determined) \\
\hline
\end{tabular}

no single diagnostic sign or symptom that will differentiate between acute sinusitis and acute dental pain. Rather, a diagnosis is reached based on a combination of clinical and, if appropriate, radiological signs, along with patient symptoms. (Table 2) Orofacial pain without nasal obstruction, nasal discharge or impaired smell sense is unlikely to be sinogenic. In a specialist setting using fibre-optic techniques, direct examination of the osteomeatal complex may show pus, which confirms a diagnosis of sinusitis. (Fig. 2) A diagnosis of sinusitis in the absence of inflammation or pus in the middle meatus would be incorrect. Acute sinusitis generally does not cause facial swelling. Exceptions are acute infection involving the anterior ethmoids or frontal sinuses which can cause medial canthal swelling or glabellar swelling respectively; 


\section{Table 2 Symptoms and signs of acute sinogenic and dental pain}

\begin{tabular}{|c|c|}
\hline \multirow[t]{5}{*}{ Specific sinogenic } & Unilateral nasal obstruction \\
\hline & Unilateral nasal discharge \\
\hline & Observation of pus in middle meatus (specialist setting) \\
\hline & Concurrent or recent upper respiratory tract infection \\
\hline & Increased pain on vertical change in head position \\
\hline \multirow[t]{5}{*}{ Shared sinogenic and dental } & Increased pain with changes in atmospheric pressure \\
\hline & Unilateral maxillary pain \\
\hline & Disturbance of sleep \\
\hline & Facial swelling (rare cases of acute ethmoid or frontal sinusitis) \\
\hline & $\begin{array}{l}\text { Buccal sulcus swelling (very rare cases of maxillary sinusitis when } \\
\text { the antrum is large) }\end{array}$ \\
\hline \multirow[t]{5}{*}{ Specific dental } & Increased pain with temperature changes when eating or drinking \\
\hline & Tooth mobility \\
\hline & Painful fractured, carious or heavily restored tooth \\
\hline & Buccal sulcus swelling adjacent to tooth that is cause of symptoms \\
\hline & Specific dental or periapical radiographic signs \\
\hline
\end{tabular}

and the very occasional case of acute maxillary sinusitis when the antrum is large and there is expansion of the thin lateral wall into the oral cavity. Acute buccal sulcus or facial swelling should be regarded as odontogenic until proven otherwise.

Treatment of acute sinusitis is based on relief of symptoms and does not involve antibiotics unless the patient is pyrexial or there is evidence of spread of infection beyond the confines of the sinus. ${ }^{8}$ Rather, treatment is based on topical nasal decongestants and saline irrigation of the nasal cavity. Topical decongestants such as ephedrine or xylometazoline constrict the nasal lining, widening the paranasal sinus ostia, facilitating drainage by ciliary activity. Most decongestants are now provided in a spray delivery device and are easily administered. Droplet preparations require more careful administration to be effective. (Fig. 3) Excessive decongestant usage will cause localised nasal discomfort. Generally, nasal decongestants should not be used for more than 7 days because of rebound mucosal swelling when the medication is stopped. ${ }^{9}$ Saline irrigation of the nasal cavity is the equivalent of a warm salty mouthwash in that it shifts surface debris and will facilitate sinus drainage. ${ }^{10}$ In practice this is delivered using a $10 \mathrm{ml}$ or $20 \mathrm{ml}$ syringe with the patient vigorously washing out their nasal cavity while leaning over a sink. Proprietary spray and pump delivered devices are also available.

When infection is spreading beyond the confines of the sinuses or the patient is pyrexial, with a pussy nasal discharge, as a first-line measure amoxicillin remains the antibiotic of choice. However, for those patients in whom there is a poor clinical response to amoxicillin, a recent generation cephalosporin antibiotic may be indicated. For those patients allergic to penicillins, doxycycline or clarithromycin may be prescribed. ${ }^{11}$ If a patient is clinically unwell, or shows signs of orbital involvement, urgent referral to a hospital setting is recommended.

Although general dental practitioners will not be prescribing nasal steroids or antihistamines, these items are sometimes prescribed for acute sinusitis but have no clinical role in reducing patient symptoms.

Chronic rhinosinus disease will generally not cause facial pain and the dental surgeon is unlikely to be making a diagnosis of chronic maxillary sinusitis when a patient presents with orofacial pain. However, the dental team should have a basic knowledge of therapies for chronic rhinosinal disease. ${ }^{3}$ Treatment is usually decided on the presence or absence of nasal polyps, which can impede sinus drainage. (Fig. 1) Treatment of chronic
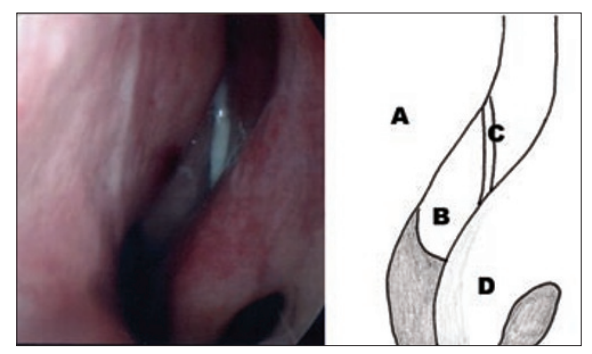

Fig. 2 Endoscopic view of the left nasal space with pus arising from the left maxillary ostium because of chronic sinusitis. $A$ is the deviated nasal septum. $B$ is the middle turbinate. $C$ is pus within the middle meatus. $D$ is the inferior turbinate

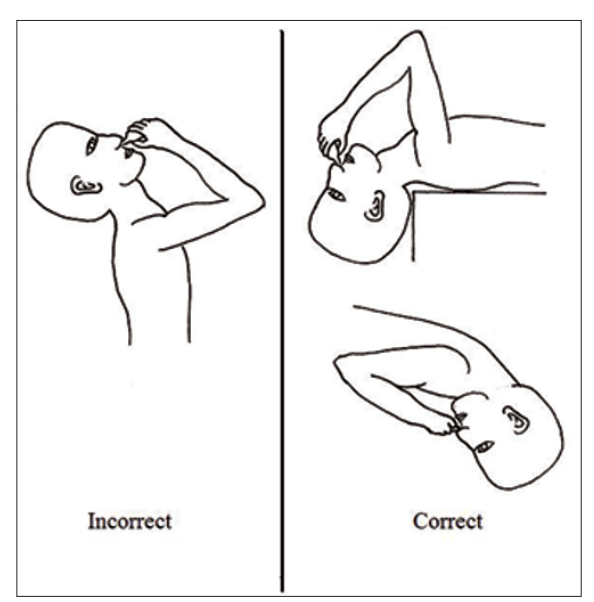

Fig. 3 Illustration of correct application technique of nasal drops to ensure accurate delivery to the middle meatus. Incorrect application results in the medicament running along the nasal floor into the pharynx bypassing the middle meatus. This technique is not necessary for spray delivery devices

disease, namely nasal congestion and discharge, is the same as for acute disease, with nasal irrigation and nasal decongestants in the first instance. Nasal decongestants may be used for a prolonged period on the basis that their use is restricted to once daily. ${ }^{12}$ When polyps are present, steroids, either topical or systemic, may be prescribed. ${ }^{13}$ Chronic disease or recurrent acute disease that does not respond to conventional medical therapy may require surgery. Following assessment by an ear, nose and throat surgeon, treatment aimed at restoring normal mucociliary function and clearance of the sinuses may be undertaken. ${ }^{14}$ This can involve treating a deviated nasal septum, removing polyps, removing or trimming turbinates, or increasing the size of the ostium from the maxillary sinus and removal of excess tissue in the middle meatus. This treatment is now regularly undertaken with the use of fibre-optic devices because of 
reduced morbidity as compared to more open traditional surgical techniques.

Retention cysts may occur within the maxillary sinus and arise from inflammation of the sinus lining, such that the secretory duct becomes obstructed, and have been observed in up to $14 \%$ of people living in industrialised environments. Retention cysts commonly occur on the floor of the maxillary sinus, are frequent coincidental findings on dental radiographs and cross-sectional imaging, and are often mistaken for sinister sinus disease or attributed to a dental aetiology. (Fig. 4) No treatment is required. ${ }^{15}$

Mucoceles arise when the drainage of the sinus is occluded such that mucus collects and can completely fill the sinus. They can occur in any of the paranasal sinuses, but mostly the frontal. The maxillary sinus is involved in only 10\% of cases. Mucoceles can also lead to bone expansion due to the pressure effect. ${ }^{16}$

Mucociliary function is impaired when the paranasal sinuses are exposed to high dose radiation as in radiotherapy, such that the patient may be predisposed to chronic rhinosinal disease. ${ }^{17}$ The same event may occur in patients with cystic fibrosis due to thick mucoid secretions and recurrent infections with scarring of the sinus lining. ${ }^{18}$

\section{Maxillary sinus disease of dental origin}

Approximately $10-12 \%$ of cases of inflammatory maxillary sinus disease are of dental origin. ${ }^{19}$ Most relate to pulpal necrosis and periapical disease, but also advanced periodontal disease, and oro-antral communications following dento-alveolar surgery. Extruded pulp space filling materials will act as local irritants when displaced into the maxillary sinus, and have predisposed to fungal infections such as aspergillosis. ${ }^{20}$ During endodontic treatment sodium hypochlorite solution may be inadvertently passed through into the maxillary sinus. Most patients will simply experience a taste of bleach in the nasopharynx, but a few will experience a localised inflammatory response. Increasingly dental implants are being displaced into the maxillary sinus where they will act as local irritants in the same way that displaced teeth or roots will. Where possible, displaced foreign bodies should be removed from the maxillary sinus, which increasingly is being performed
Table 3 Radiographic features of the healthy maxillary sinus, soft tissue sinus disease and odontogenic lesions

\begin{tabular}{|l|l|} 
Healthy maxillary sinus & Trabecular pattern of bone of lateral wall is visible superimposed on \\
\end{tabular} radiolucency of sinus

\begin{tabular}{ll}
\hline \multirow{5}{*}{ Soft tissue lesion of sinus } & $\begin{array}{l}\text { Sinus floor and walls are imaged as a thin continuous white line } \\
\text { (corticated outline) }\end{array}$ \\
\hline & $\begin{array}{l}\text { Small blood vessels are visible as fine radiolucent channels as they } \\
\text { traverse the lateral sinus wall }\end{array}$ \\
& $\begin{array}{l}\text { Lesion is viewed as radio-opaque when compared to air of sinus, } \\
\text { without a corticated margin }\end{array}$ \\
\cline { 2 - 2 } & $\begin{array}{l}\text { In benign disease the walls of the maxillary sinus are imaged as a thin } \\
\text { continuous white line }\end{array}$ \\
\hline $\begin{array}{l}\text { In malignant, infective or expansile disease the walls of the sinus are } \\
\text { resorbed such that the corticated outline is discontinuous }\end{array}$ & $\begin{array}{l}\text { In malignant or rapidly expansile disease the roots of the maxillary teeth } \\
\text { may be resorbed }\end{array}$ \\
\hline Odontogenic lesion & \begin{tabular}{l} 
Dental disease, namely caries or resorption, is visible \\
\hline
\end{tabular} \\
\hline $\begin{array}{l}\text { The periodontal ligament space is widened apically or discontinuous. } \\
\text { The lamina dura may be missing. }\end{array}$ \\
\hline $\begin{array}{l}\text { As periapical tissues or cysts expand into the sinus space the corticated } \\
\text { outline of the sinus floor is elevated (the antral halo effect) }\end{array}$ \\
\hline $\begin{array}{l}\text { When superimposed on the air space of the sinus there is limited or no } \\
\text { trabecular pattern and limited blood vessel channels }\end{array}$ \\
\hline
\end{tabular}

using endoscopic techniques. When an oroantral fistula is treated it is often necessary to treat concurrent chronic sinus infection, as failure to do so will result in failure of treatment. Therefore, when sinus drainage is impaired through concurrent rhinosinal disease, irrigation of the sinus with removal of diseased tissue may be insufficient and middle meatal surgery may also be necessary before normal mucociliary clearance can be re-established.

Dental disease extending into the maxillary sinus is uncommon. However, odontogenic cysts and tumours will often expand into the maxillary sinus. (Fig. 5) Equally, changes within the maxillary sinus related to inflammation may occasionally be misinterpreted as odontogenic disease when viewed on radiographs. (Fig. 6) Dentists may occasionally experience difficulty interpreting radiographs to determine whether or not disease or changes arise from within the sinus or are of odontogenic origin. The presence or absence of the maxillary sinus floor, periodontal ligament space or lamina dura, trabecular pattern of bone and blood vessel channels within the lateral maxillary wall will aid a differential diagnosis. (Table 3) (Figs 7, 8)

While radiographic techniques available to the dental practitioner may occasionally show disease within the maxillary sinus, the taking of dental radiographs, particularly dental panoramic tomograms, in cases of

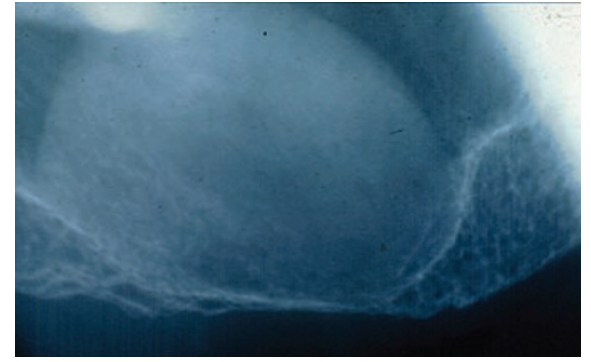

Fig. 4 Periapical radiograph showing a dome shape, non-corticated radiopacity in the floor of the maxillary sinus. The sinus floor is intact and a trabecular pattern of bone with blood vessels is observed superimposed on the radiopacity. This is a retention cyst

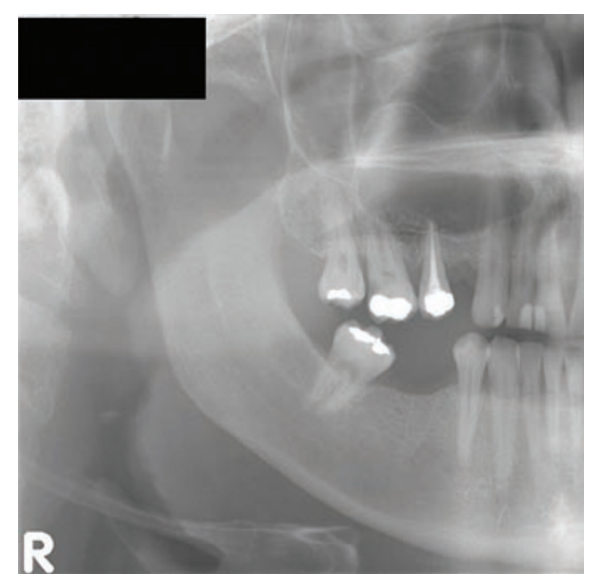

Fig. 5 Sectional dental panoramic tomogram showing a corticated, unilocular radiolucency extending into the right maxillary sinus. There is widening of the periodontal ligament space over the UR5 tooth. The trabecular pattern of bone does not extend over the radiolucency and blood vessel channels are not seen. This is a radicular cyst arising from the UR5 tooth 


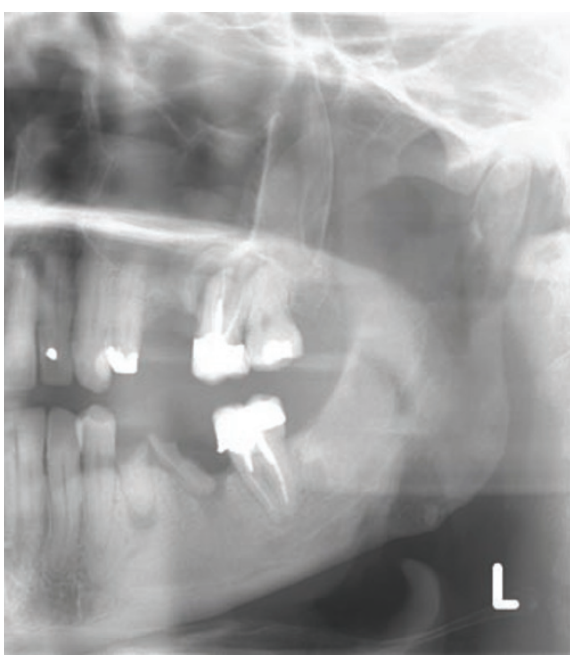

Fig. 6 Sectional dental panoramic tomogram showing a diseased UL6 tooth with periapical bone loss. The non-corticated, dome-shaped radiopacity within the maxillary sinus is a retention cyst and not related to the dental disease. The bone density of the hard palate is superimposed on the maxillary sinus

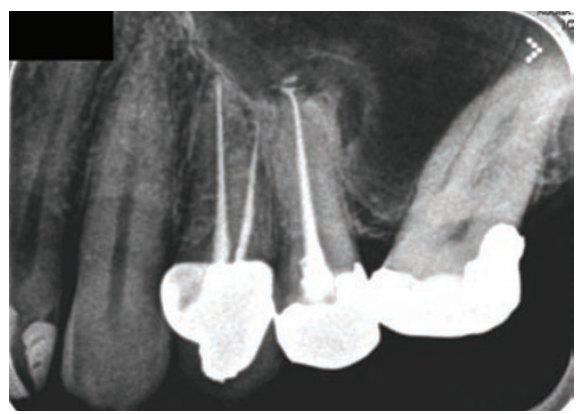

Fig. 7 Periapical radiograph showing dental disease. The large radiolucency shows a trabecular pattern with blood vessel channels excluding an odontogenic cyst, demonstrating an enlarged maxillary sinus. The UL5 tooth has a periapical lesion demonstrating an antral halo as the periosteum of the sinus floor is elevated. Note the lack of lamina dura on the UL5

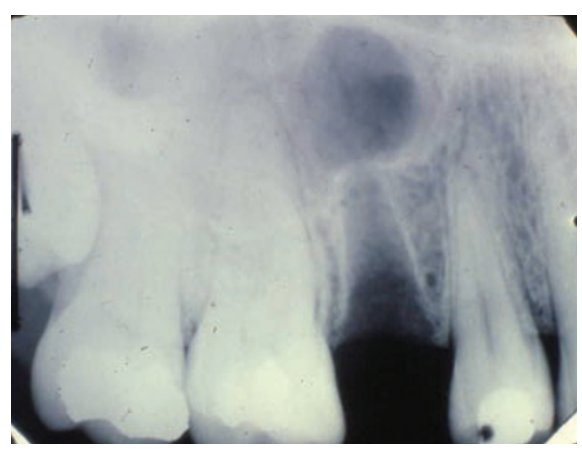

Fig. 8 Periapical radiograph showing a radiolucency above the apex of the extracted UR5, superimposed within the corticated outline of the maxillary sinus. Note the intact lamina dura of the tooth socket, the presence of a trabecular pattern of bone and fine channels caused by the presence of blood vessels. This is an antral locule rather than a periapical lesion from the UR5

\section{Table 4 Some signs and symptoms that may be suspicions for maxillary sinus malignancy}

\begin{tabular}{l}
\hline Unilateral orofacial pain \\
\hline Unilateral firm, non-infective facial swelling \\
\hline Nasal obstruction \\
\hline Epistaxis \\
\hline Diplopia \\
\hline Trismus \\
\hline Non-healing extraction site \\
\hline Infra-orbital parasthesia \\
\hline Mobility of teeth in the absence of periodontal or periapical disease \\
\hline Resorption of roots of teeth \\
\hline Spontaneous oro-antral fistula formation \\
\hline Loss of radiopaque outline of maxillary sinus \\
\hline
\end{tabular}

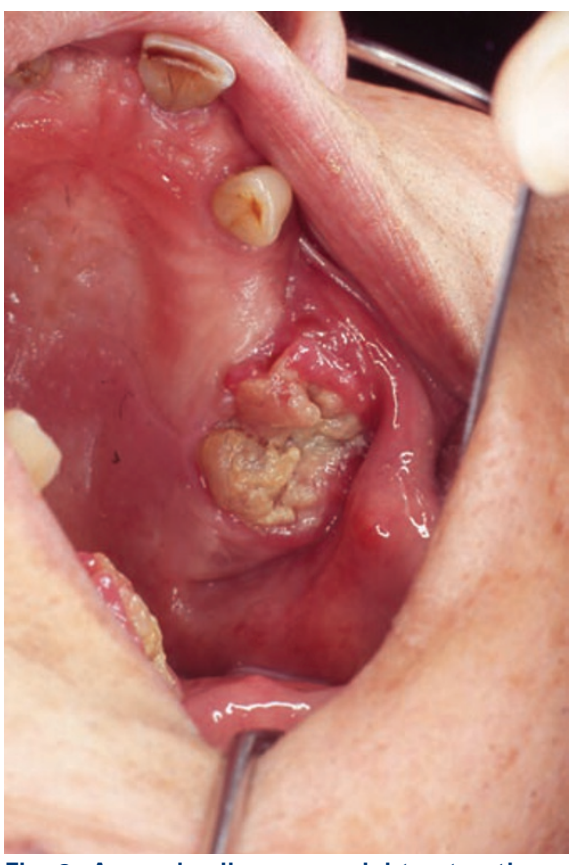

Fig. 9 A non-healing upper right extraction site with a spindle cell squamous carcinoma arising from the maxillary sinus

acute sinusitis is contra-indicated, unless it is to exclude a dental cause for the patient's symptoms. Dental practitioners who have access to cone beam computed tomography will often intentionally or unintentionally also obtain images of the paranasal sinuses and have a legal responsibility to ensure that any abnormalities are accurately reported and acted upon. ${ }^{21}$

\section{Malignant disease of the maxillary sinus}

Malignancy arising within the paranasal sinuses is relatively rare, constituting $1.0 \%$

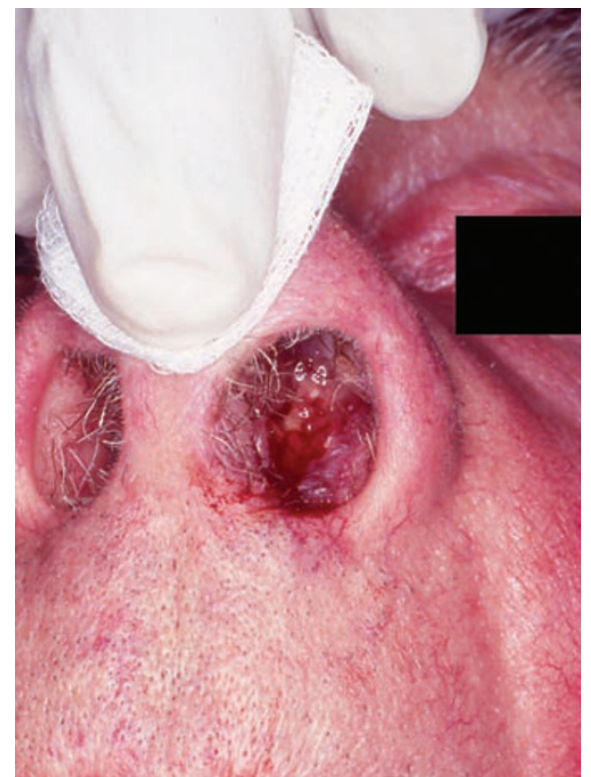

Fig. 10 Left sided nasal obstruction with epistaxis in a patient with an advanced squamous cell carcinoma of the left maxillary sinus. Examination also showed lateral expansion of the alveolus

of all malignancies, with approximately $80 \%$ of these malignancies arising in the maxillary sinus with a lesser prevalence in the ethmoid sinus. Malignant disease of the sphenoid and frontal sinuses is very rare. ${ }^{22}$ Almost $80 \%$ of malignancies are squamous cell carcinomas, with acinic cell carcinomas causing 10\%. (Table 1) Metastatic disease presents in the bone and expands into the sinus space.

Malignant disease of the paranasal sinuses unfortunately often presents at a late stage when the tumour has become large enough to cause symptoms. The 
mucosa of the paranasal sinuses is not as easily accessible as the oral mucosa for routine inspection and early mucosal abnormalities are not seen or investigated.

The dental professional can play a role in the diagnosis of a patient with maxillary sinus malignancy. A combination of patient symptoms and clinical signs should arouse suspicion of maxillary sinus malignancy, warranting immediate referral to an appropriate specialist. (Table 4) (Figs 9-11) Unfortunately, it has been known for patients to be treated for long periods on the assumption that their symptoms arise from chronic inflammatory rhinosinal disease, only for a diagnosis of malignancy to be made at a later date.

Malignancy of the maxillary sinus is managed by multidisciplinary teams with input from the surgical specialties of oral and maxillofacial, ear, nose and throat, and plastic and reconstructive surgery. It is not the intention of this paper to outline treatment for sinonasal malignancy and interested readers are referred to more comprehensive texts. ${ }^{22}$

\section{Fungal disease of the maxillary sinus}

Most fungal disease of the maxillary sinus involves the organism Aspergillus which lives within moulds and spores and is regularly inhaled into the respiratory system. When infection occurs with Aspergillus in relation to dental foreign materials, the infection is normally contained within the confines of the maxillary sinus. ${ }^{20}$ Foci of infection may lead to dystrophic calcification and the formation of rhinoliths, which may be seen on dental radiographs. (Fig. 12) Large rhinoliths are known as fungal balls. Treatment is normally surgical with removal of any predisposing cause, and this is also increasingly being provided endoscopically with the aim of restoring normal mucociliary function.

However, in the immuno-compromised patient, as in poorly controlled diabetes mellitus, HIV infection and chemotherapy, fungal infections such as aspergillosis or mucormycosis may extend beyond the confines of the sinus into the orbit, temporal fossa or oral cavity producing symptoms and signs suggestive of malignant disease. Occasionally disease extends to the brain. ${ }^{23}$

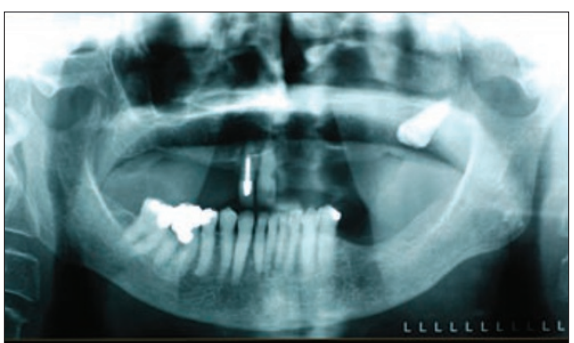

Fig. 11 A dental panoramic tomograph demonstrating complete loss of bone in the left maxillary alveolus due to antral carcinoma. The UL8 tooth is embedded within the tumour mass. The soft tissue shadow demonstrates the tumour extension into the oral cavity

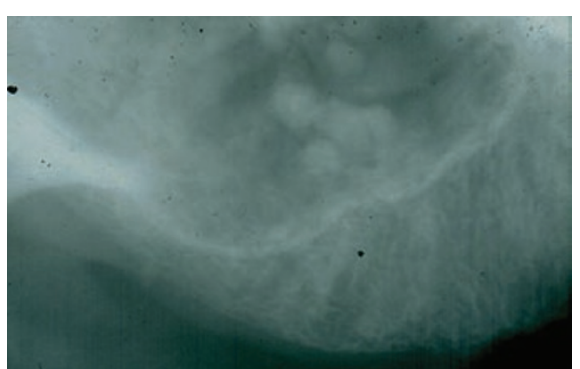

Fig. 12 Periapical radiograph of posterior maxilla showing multiple spheroidal calcifications (antroliths) within a thickened antral lining. These are almost certainly an example of dystrophic calcification within chronically inflamed tissue

While most of these patients will be clinically unwell and already within a hospital setting, the vigilant dental professional has a role to play in identifying early signs or symptoms. (Table 4)

\section{CONCLUSION}

The aim of this paper has been to enlighten the dental professional in the disease processes that may involve the maxillary sinus. Of importance is the accurate diagnosis of acute rhinosinusitis in treating orofacial pain and the shift away from routine antibiotic therapy. When viewed together, specific signs and symptoms that can be suggestive of maxillary sinus malignancy are emphasised. The various radiographic features that guide the dental professional when viewing radiographs; and determining whether or not changes are related to disease or health, and whether the disease is dental or sinogenic have been outlined.

1. Paranasal sinus anatomy and function. http://www. utmb.edu/otoref/grnds/paranasal-sinus-2002-01/ paranasal-sinus-2002-01.htm. Accessed 22 November 2010.
2. Eberhardt J A, Torabinejad M, Christiansen E L. A computed tomographic study of the distances between the maxillary sinus floor and the apices of the maxillary posterior teeth. Oral Surg Oral Med Oral Pathol 1992; 73: 345-346.

3. Schaefer S D. Rhinology and sinus disease: a problem-oriented approach. St Louis: Mosby, 1998.

4. Erkan M, Aslan T, Ozcan M, Koç N. Bacteriology of antrum in adults with chronic maxillary sinusitis. Laryngoscope 1994; 104: 321-324.

5. Bachert C, Hörmann K, Mösges R et al. An update on the diagnosis and treatment of sinusitis and nasal polyposis. Allergy 2003; 58: 176-191.

6. Scully C, Felix D H. Oral medicine - update for the dental practitioner: orofacial pain. Br Dent J 2006: 200: $75-83$.

7. Jones N S. Sinus headaches: avoiding overand mis-diagnosis. Expert Rev Neurother 2009; 9: $439-444$

8. Chan Y, Kuhn F A. An update on the classifications, diagnosis and treatement of rhinosinusitis. Curr Opin Otolaryngol Head Neck Surg 2009; 17: 204-208.

9. Graf P. Long-term use of oxy- and xylometazoline nasal sprays induces rebound swelling, tolerance, and nasal hyperreactivity. Rhinology 1996; 34: 9-13.

10. Harvey R, Hannan S A, Badia L, Scadding G. Nasal saline irrigations for symptoms of chronic sinusitis. Cochrane Database Syst Rev 2007: CD006394.

11. Sinus and Allergy Health Partnership. Antimicrobial treatment guidelines for acute bacterial rhinosinusitis. Otolaryngol Head Neck Surg 2000; 123: 5-31.

12. Yoo J K, Seikaly H, Calhoun K H. Extended use of topical nasal decongestants. Laryngoscope 1997; 107: 40-43.

13. Lund V J, Black J H, Szabó L Z, Schrewelius C, Akerlund $A$. Efficacy and tolerability of budesonide aqueous nasal spray in chronic rhinosinusitis patients. Rhinology 2004; 42: 57-62.

14. Khalil $H$, Nunez D A. Functional endoscopic sinus surgery for chronic rhinosinusitis. Cochrane Database Syst Rev 2006: CD004458.

15. Wang J H, Jang $Y$ J, Lee $B$ J. Natural course of retention cysts of the maxillary sinus: long-term follow-up results. Laryngoscope 2007; 117: $341-344$

16. Ling FT K. Mucoceles of the paranasal sinuses. http://drfling.hyperphp.com/Notes/Mucoceles $\% 20$ of $\% 20$ the $\% 20$ Paranasal\%20Sinuses.pdf. Accessed 22 November 2010.

17. Kamel R, Al-Badawy S, Khairy A, Kandil T, Sabry A. Nasal and paranasal sinus changes after radiotherapy for nasopharyngeal carcinoma. Acta Otolaryngo/2004; 124: 532-535.

18. Gysin C, Alothman G A, Papsin B C. Sinonasal disease in cystic fibrosis: clinical characteristics, diagnosis, and management. Pediatr Pulmonol 2000; 30: 481-489.

19. Mehra P, Jeong D. Maxillary sinusitis of odontogenic origin. Curr Allergy Asthma Rep 2009. 9: 238-243.

20. Burnham $R$, Bridle $C$. Aspergillosis of the maxillary sinus secondary to a foreign body (amalgam) in the maxillary antrum. Br J Oral Maxillofac Surg 2009; 47: 313-315.

21. Department of Health. The lonising Radiation (Medical Exposure) Regulations 2000. Department of Health, 2007. http://www.dh.gov.uk/prod_consum_dh/groups/dh_digitalassets/@dh/@en/ documents/digitalasset/dh_064707.pdf. Accessed 22 November 2010

22. Katzenmeyer K, Pou A. Neoplasms of the nose and paranasal sinuses. http://www.otohns.net/default. asp?id=14054.

23. Sarti E J, Blaugrund S M, Tang Lin P, Camins M B. Paranasal sinus disease with intracranial extension: aspergillosis versus malignancy. Laryngoscope 1988; 98: 632-635. 